\title{
The stressors of nurses of critical care units
}

\section{Masoomeh Aghamohammadi*1 and Mansooreh Karimollahi ${ }^{2}$}

Address: ${ }^{1}$ Faculty of Nursing and midwifery, Ardabil Medical Sciences University, Ardabil, Iran and ${ }^{2}$ Faculty of Nursing and midwifery, Ardabil Medical Sciences University, Ardabil, Iran

* Corresponding author

from International Society on Brain and Behaviour: 3rd International Congress on Brain and Behaviour

Thessaloniki, Greece. 28 November - 2 December 2007

Published: 17 April 2008

Annals of General Psychiatry 2008, 7(Suppl I):SI49 doi:10.1186/1744-859X-7-SI-SI49

This abstract is available from: http://www.annals-general-psychiatry.com/content/7/SI/SI 49

(c) 2008 Aghamohammadi and Karimollahi; licensee BioMed Central Ltd.

\section{Background}

Critical care units are the most sensitive professional units of hospital, and one of the stressors in nursing profession is working in these units. Observing dying patients, doing more work, communicational problems and other environmental factors are the main problems of these nurses. This study was performed to recognition problems of nurses working in critical care units of Ardabil hospitals.

\section{Materials and methods}

This is a descriptive study. The study population was the all of nurses working in critical units of Ardabil hospitals, contains 48 nurses and all of them were selected for the sample. The mean for collecting data was questionnaire.

\section{Results}

In this study $46 \%$ of nurses mentioned that new experiences in profession is the first problem and not to being able for decision-making about living and dying of patients is the second.

\section{Conclusions}

Surely cognition of the problems of nurses that working with patient directly can decrease potential problems and increase quality and quantity of nursing care. 